\title{
AGILE PROJECT MANAGEMENT IN GOVERNMENTAL ORGANIZATIONS - METHODOLOGICAL ISSUES
}

\author{
Margarita Bogdanova1, Evelina Parashkevova², Mariela Stoyanova ${ }^{3}$ \\ ${ }^{1}$ Professor, Ph.D., Tsenov Academy of Economics - Svishtov, Bulgaria, \\ m.bogdanova@uni-svishtov.bg \\ ${ }^{2}$ Head Assist. Professor, Ph.D., Tsenov Academy of Economics - Svishtov, Bulgaria, \\ e.parashkevova@uni-svishtov.bg \\ ${ }^{3}$ Assist. Professor, Ph.D., Tsenov Academy of Economics - Svishtov, Bulgaria m.stoyanova@uni- \\ svishtov.bg
}

\begin{abstract}
The main purpose of the article is to present a new methodology for Agile project management in the public sector and to discuss the issues related to its implementation in governmental organizations. The methodology is hybrid insofar as it implements agile tools in a traditional hierarchical environment. The approach aims to overcome some of the weaknesses of public sector project management, such as the cumbersome communication system, the multilevel hierarchy in reporting levels, ex-post control, high risk, large bureaucracy, voluminous documentation, etc.
\end{abstract}

Keywords: Agile project management, public administration, methodology implementation.

\section{INTRODUCTION}

Efficiency and effectiveness of public administration are a permanent focus of public attention. The search for new approaches to work in the public sector in the 1980s led to the emergence of the approach known as New Public Management. The basic idea behind this approach is to make public sector organizations "businesslike" by using business models in the delivery of public services.

At the same time, the business sector also develops different approaches and models to improve the way it works. One of the most up-to-date trends is the agile project management. It emerged in the IT sector in 2001, but gradually entered other, non-software industries. However, applying the approach to the public sector requires a specific transformation of the agile methodology, insofar as the two sectors are radically different. The public sector is pre-determined by regulations, insufficiently oriented towards service users, bureaucratized and hierarchically organized. All this represents an obstacle to agile project management, which aims to provide autonomous project teams, frequent and honest feedback from clients and other stakeholders, flexibility of project scope, etc.

The main purpose of the article is to present the authors' concept of agile project management methodology in the public sector and to discuss the issues related to its implementation in governmental organizations.

The research problem of the study is the agile project management. The research area of the study is the feasibility of agile project management in the public sector, not only with IT services but also in other public projects - infrastructure, in creating local strategies and development plans with wide stakeholder involvement, as well as in the implementation of these projects, particularly related to regional marketing (attracting investors, retaining and attracting local residents, tourists, etc. 


\section{LITERATURE REVIEW}

Agile project management emerges in response to several major problems in the work of the IT sector (Beck, 2001). Generally, they are associated with increasing customer complaints, breach of contracted budgets and duration, which is why it is necessary to constantly conclude annexes for extension of time, changes in scope, product specifications for the project, etc. In general, less than $1 / 3$ of the projects are implemented successfully (Hass, 2007), which is a powerful signal for systematic errors in their management. It is becoming increasingly clear that the traditional project management approach applied since the second half of the 20th century is ineffective.

The traditional approach applied in public sector organizations is even less successful. With them, the scope of projects is clearly defined, emphasizing highly controlled processes, strictly kept documentation and the high level of accountability. In objective terms, these are all positive features. However, they have negative consequences in a more dynamic external and internal design environment. Through the prism of public sector project implementation, they reflect in difficult team communication due to high hierarchy and excessive bureaucratization of project processes in the pursuit of enhancing control and accountability.

The conceptual differences that agile thinking offers represent the inversion of the manager's triangle as the scope of the project changes from fixed to a variable quanity, while the time and cost of executing changes from variable to fixed. The goal is at the same cost and for the same time to improve work on a project so that customers remain satisfied. The differences can be seen graphically in Fig. 1 .

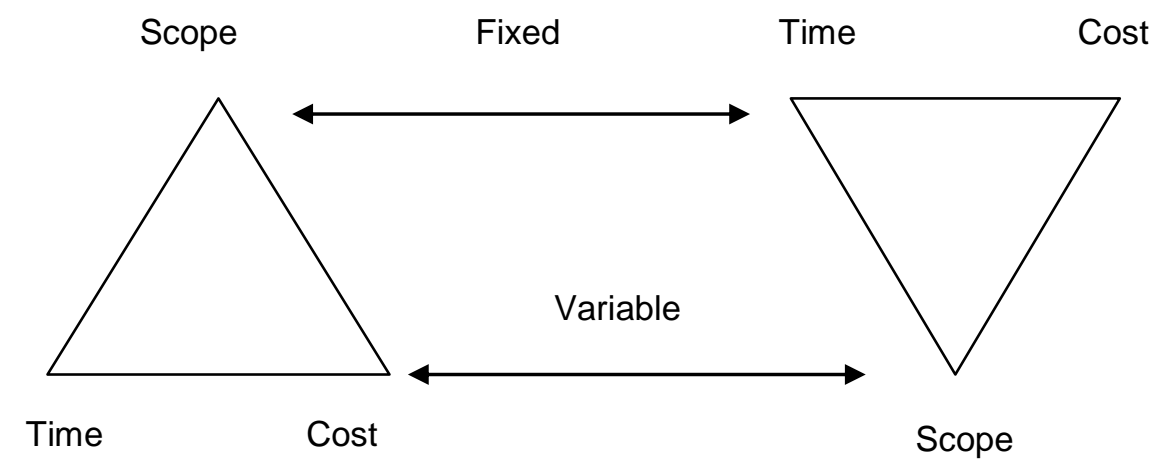

\section{Traditional project management}

Agile project management

Fig. 1 Differences between traditional and agile project managemen (Owen et al. 2006).

In the pursuit of more added value and flexible solutions, agile project management is governed by four basic principles that have become popular in Agile Manifesto: (Agile handbook Philosophie):

- Investing in people and relationships between them is a priority over detailed process scheduling;

- The final outcome of a project is more important than generating comprehensive implementation documentation;

- Focusing on customer interaction and feedback is more important than the pursuit of comprehensive legal regulation;

- The need to respond to changes is far more essential for achieving the main goals than the strict adherence to plans.

The fundamental principle of agile management, which distinguishes it from the traditional one, is the desire to add value at every stage of implementation, in a creative and innovative way (Agile Project Management QuickStart Guide, 2014). In this regard, limitations accompanying the traditional approach are in contrast to the open to a change process, typical of the agile approach.

The advantages of the agile approach can be outlined in several directions. They start with the organizational structure which is flexible while the tasks are performed iteratively. This makes it possible to draw conclusions at each iteration and to modify execution if necessary. Process monitoring is performed at shorter time intervals and does not allow transition to the next work cycle without the previous one being approved.

It is of utmost importance that customers are involved in the various stages of the tasks, which provides 
constant feedback from them and ensures that the project outcome meets their expectations to the highest degree. In the traditional approach, it is also important that customers are involved, but this process takes place before implementation begins and does not allow them to detect changes in their expectations that occur at a later stage.

Another advantage of the agile approach is the focus on the implementation of project activities. Agile management brings to the fore the final outcome, rather than the formal and directive processes.

The core of agile project management are several methodologies, the most widely used being Scrum, Canban and Lean.

The concept of Scrum focuses on the use of an empirical process that allows teams to respond rapidly, efficiently, and effectively to change. This approach concentrates not only on adding any value, but on the highest value defined by customers (Schwaber, 2004). Jeff Sutherland argues the need for a new way of thinking, stating that the main goals of traditional management are two - control and predictability, which, in a dynamic environment, cannot always respond adequately to the changing environment. At the same time, Scrum is an approach that encourages creativity in dealing with uncertainty. It places a structure around the learning process, enabling teams not only to achieve an outcome, but also to choose the way to achieve it (Sutherland, 2014b).

The Lean methodology, in turn, seeks to add more value while trying to eliminate anything that is not worthwhile. There are five basic steps in implementing Lean: defining value; eliminating all that does not add value; creating shorter work cycles; giving teams more freedom; providing customer feedback (The Five Steps of Lean Implementation, 2019a).

However, the implementation of Lean does not always lead to improvements. Usually, the main reason is the lack of flexibility in the system in which it is implemented and the inability to follow its principles. Problems may also arise when an organization is not sufficiently well prepared to move to the new mode of operation.

Kanban, in turn, aims to change the traditional way of executing projects, but in a smoother way without introducing entirely new roles to project teams or new terminology of work processes. When presenting the Kanban approach to a team working in the traditional way, it is emphasized that the work the team has done so far will not change in nature. What will be changed is the way the team chooses any of the next tasks. (Brechner, 2015). The main tool that Kanban uses is to visualize the progress of tasks on a board. In this way, each person in a team is informed about the stage of the ongoing work and what the next task is.

Other varieties of agile approaches, methods, project management frameworks such as Crystal, DSDM and DevOps also exist. However, most often large companies use a combination of the main three.

Each of the agile approaches has its advantages and disadvantages and the main task of organizations that have decided to adopt agile project management is to adapt the chosen method to their own needs. Although the business sector, in the pursuit of being more competitive, is more open to changes and, accordingly, to using flexible techniques, the public sector could also adopt some of them in the context of the New Public Management. This step would improve organizational culture, attitudes and behaviour in administration and, step by step would change it into modern and innovative, adequate to community needs.

In literature, the issue whether the agile approach is applicable to public sector organizations has been partially studied, mainly in the field of providing digital services to internal and external users.

What is common in the studies of different authors are the reasons for the slow introduction of new methodologies in the public sector. According to experts from the Project Management Institute (Government Extension to the PMBOK® Guide Third Edition, 2002), additional factors (beyond those in the business) that affect public sector organizations are:

- Regulatory rules regarding the implementation of the managerial and socio-political responsibilities of participants;

- The need for a project team to always serve and reflect public interest.

A. Ribeiro and L. Domingues applied a case study method to a Portuguese governmental organization. They studied the feasibility of the agile project management approach in the public sector while focusing on software development in governmental organizations rather than projects in general (Ribeiro, Domingues, 2018). I.e. their study focuses on the IT sector, but in a specific organizational environment - that of governmental, regional and local organizations which have different culture and modus operandi - far different from that of the private sector. The public sector, according to the authors, is more bureaucratic and there is greater resistance to change. This makes it difficult to introduce new methodologies and approaches 
to businesses.

A number of authors have reached a similar conclusion, such as Powner (Powner, 2012), who studies the implementation of agile project management in the state and federal authorities in the USA, Kaczorowska (Kaczorowska, 2015a), Karaj and J. Little (Karaj, Little, 2013), who presented their studies at various conferences on Agile methodologies. They focus on the organizational culture in the public sector, which is often very hierarchical, with rules and policies with poor flexibility and formal documentation, especially with regard to communication.

It seems that while for the private sector the volume of publications related to agile PM is huge and steadily increasing, for the public sector studies are too scarce. It is also unclear what the outcomes are for organizations where the method is already applied (Conforto et al. 2014a).

A study conducted in 2016 (Wisitpongphan, Khampachua, 2016b) identifies two major challenges in the implementation of agile methodologies:

- Lack of involvement and participation of final users in a project;

- Lack of flexibility to integrate requirements during the project development.

J. Nuottila and K. Aaltonen in their 2016 article identify seven categories of challenges in the implementation of agile methodologies in the public sector (Nuottila, Aaltonen, Kujala, 2016a):

- Documentation - Employees misunderstood the difference between the lack of required documentation and working without detailed documentation (which is the principle of agile projects);

- Education, experience and dedication;

- Communication and stakeholder involvement - It is important to identify the stakeholders in the beginning of the project and to communicate with them when necessary with respect to all important decisions. This is a standard problem in both businesses and the public sector, although there is some difference as to who stakeholders are. In the public sector, we usually talk about the needs of large social groups, which may be difficult to cover or difficult to communicate with. In any case, this could be a lengthy process because of the need to involve a large number of participants.

- Roles in a project - a change in methodology leads to changes in roles which can cause lack of responsibility simply because employees don't understand their new roles;

- Developing team localization - it was identified that teams, in some projects,worked away making coordination and communication more difficult;

- Legislation - J. Nuottila and K. Aaltonen's study identifies some confrontation between legislation and the principles of agile methodologies, such as delivery dates, costs, information confidentiality, etc.;

- Architectural complexity of software systems - Due to the complexity of the systems, the study reports some difficulty with integrating the agile methodology into the old systems.

Although they are designed primarily for IT teams working in the public sector, most of these challenges can be related to other types of projects.

Although rarely, scientific reports on successful practices can be found in literature. A study conducted by the University of Seville (Torrecilla-Salinas et al. 2013) presents the outcomes of an agile methodology application (Scrum, in this case) in a public organization. A project planning and estimation technique was used and it was verified that the planned project outcomes were achieved in almost all cases precisely through the Scrum methodology.

Another study related to the banking sector, aiming to assess the conditions for applying an agile methodology in the public sector, concluded that there is no great preference for agile practices (Roses et sl. 2016a).

Similar is the conclusion of the Russian researchers Altukhova, Vasileva and Slavin (Altukhova, Vasileva, Slavin, 2016). They studied public sector attitudes in Russia to agile project management application, but concluded that, unlike business organizations, the motivation for informal leadership is low in government offices, and self-organization and self-management are not developed. The authors consider these to be serious barriers to the introduction of agile project management, although this could still be possible under certain circumstances.

Currently, a developed methodology for agile project management in the public sector does not exist. 
IJASOS- International E-Journal of Advances in Social Sciences, Vol. VI, Issue 16, April 2020

Therefore, the present study could be a useful starting point in this regard for both theory and practice.

\section{RESEARCH METHODOLOGY}

The research approach used to develop an agile project management methodology in the public sector is based on standard scientific methods, mainly of a qualitative nature.

A wide range of secondary sources of information - scientific publications, analyses, methodologies, guides, best practices and standards for agile project management, both in businesses and in the public sector have been studied. Through content analysis, Collects participant meanings, Focuses on a single concept or phenomenon and induction, basic trends in the development and application of agile project management methods, significant effects for organizations and major problems are outlined.

On this basis, specific characteristics and special features of agile management methods are defined through deduction, which through research synthesis methods are implemented in the basic principles of the structured methodology for agile project management in the public sector.

The specific character and normative regulation of the public sector activity necessitated the development of a technique that is inherently hybrid - a combination of conventional and agile project management. The scientific approach applied to synchronize these methodologies is related to the definition of key common ground - Develops a rationale for mixing.

The iterative approach is the basis of the methodology for agile project management in the public sector. The method of analogy and comparative analysis is used to define the main limitations and preconditions that are part of the methodology. In order to specify the processes, a graphical and mapping methods are used. By using the case method, various alternatives are presented for the process, depending on the specifics of a particular project and the organization of team work.

The methodology for agile project management in the public sector is verified, both in terms of its convergence with basic concepts and formulations of standards in the field of project management, and in terms of public sector project management practices in Bulgaria. The applied methods are a comparative analysis and a case method, while the scientific exchange is carried out through expert evaluation and indepth interviews with representatives of the Bulgarian Institute for Standardization and with officials in municipal administrations.

Within the process of verification, the hypothesis of the research team was discussed, namely that the agile project management methodology can contribute to greater efficiency and effectiveness of projects in public sector organizations, not only with projects funded by the EU Structural Funds but also in the implementation of their internal project initiatives, such as the introduction of new standards, organizational changes, etc. When these activities are considered in terms of agile project management, organizations will achieve greater public service delivery, greater transparency and stakeholder satisfaction. It received its qualitative support from practitioners who identified the main problems of conventional management and outlined organizational measures to overcome them. The proposed measures are in the context of the defined principles of agile project management. During the verification, adjustments were made to the methodology in order to increase its applicability in a real work environment.

The methodology for agile project management in the public sector is based on a systematic analysis and a traduction approach to the proposed scientific and practical solution.

\section{AGILE PROJECT MANAGEMENT METHODOLOGY}

The concept of agile project management methodology in the public sector aims to overcome some of the weaknesses of conventional project management, such as the cumbersome communication system, the multilevel hierarchy in reporting levels, ex-post control, high risk, large bureaucracy, voluminous documentation, etc.

The methodology is inherently organizational innovation as it introduces a new project management approach, which is a hybrid one between agile and traditional management. By using a specific conceptual tools, it introduces a broader understanding of projects in the public sector, emphasizing time and resource constraints and the need to achieve a fixed final outcome. It is assumed that resource provision can be budgeted (including capital expenditures and current costs), incl. loans, grants, public-private partnership funds, donations, and more. In addition to the classical concept of a project, pre-project work, such as preparing project documentation of applying for funding, procurement documents or a strategy for specifying public policy, etc. can be added here. They are also regarded as projects and agile management may be applied to their implementation. 
The concept is based on the team approach through which specific roles are assigned. Roles are project positions that are different from project duties. Agile management is implemented through them. They are dynamic. The same person may perform different roles at different intervals of project implementation.

The roles created for the needs of agile project management methodology in the public sector are as follows:

Public owner of project outcomes - the head of a public sector organization within which the project is implemented and managed.

Team leader / Project owner - this is a person who usually performes leadership functions in the organization and provides the necessary organizational conditions for the successful implementation of a project. They are responsible for meeting project objectives within the time and resources available. Usually the role of a project owner is performed by the team leader (project manager).

Task owner - responsible for the outcomes of the task assigned. They assist and guide team members in performing the iterations that fall within the scope of the task for which they are responsible. They carry out internal monitoring of the task and make decisions on changes after discussing them with the team. They direct the team when prioritizing iterations.

A Person responsible for iteration/s - a team member responsible for executing the iteration assigned. Works independently or in a team. Maintains a close relationship with the task owner responsible for the iteration currently perfomed. The role is dynamic as iterations change constantly, i.e. completed iterations are replaced with new ones.

Ordinary team members - team members who perform iterations but are not responsible for them.

Agile management master/specialist - an administration official who has experience and knowledge in the field of agile project management. Their involvement in a team is solely to ensure the implementation of the agile methodology and to assist the team in the emergence of different cases with regard to agile project management.

A Member, external to the organization - representative/s of the stakeholders involved in the project team. They may perform any of the above roles except for the roles of a project owner and a public owner of project outcomes.

In order for the methodology to work, teams should have a limited staff of 3 to 9 people. Self-organization is leading. Communication and coordination are facilitated, interaction is more efficient. Flexibility is due to the fact that team members have freedom while working, which in turn contributes to faster adaptation to changing external conditions. The team maintains optimum internal communication channels. When a project requires a larger team, for example more than 12 members, it can be organized into several smaller teams that work in parallel. An agile manager is responsible for assigning clear roles and responsibilities to ensure proper team alignment and adequate accountability.

The team learns while working, enhances products and/or services, as well as their work every subsequent cycle. Autonomous team decision-making, reducing the volume and complexity of tasks, iterations, fast feedback and self-control are the basis of the methodology.

Agile project management is characterized by rapid iterative cycles of planning and development that allow a project team to constantly evaluate its work and receive immediate feedback from other team members and, if possible, from stakeholders. Iterations are based on simple planning, on defining requirements and designing solutions that are continuously implemented throughout project implementation. This approach is similar to cyclic waves. It allows for immediate adjustments to work.

The concept of project management methodology in public sector organizations is structured in three interrelated stages, which are cyclical: Stage 1. Preparing for agile project management; Stage 2. Implementing agile project management; Stage 3. Internal monitoring. The division of stages is indicative and aims to create a better organization for methodology implementation. For each stage, inputs and outputs as well as specific implementation steps are defined. Flowcharts are created to show the various stages of the methodology, as well as matrices of rights, responsibilities and allocated roles.

During Stage 1. Preparing for agile project management, a cross-functional project team is formed. The team, on the basis of existing administration practices and the specifics of each individual project, has the autonomy to decide whether or not to apply agile management. Whenever possible, a representative of stakeholders and/or target groups is involved to ensure their participation. After its formation, the team holds a meeting to discuss and adopt rules for agile project management, incl. the tools that will be applied. The roles within the team are also assigned during this stage. The decisions made at this stage are not constant. 
When changing organization, the team, or in case of finding decisions ineffective and inoperative, they are changed.

Table 1. Responsibility matrix in Stage 1. Preparing for agile project management.

\begin{tabular}{|c|c|c|c|c|c|c|}
\hline Step & $\begin{array}{l}\text { Project } \\
\text { owner }\end{array}$ & $\begin{array}{l}\text { Public owner } \\
\text { of project } \\
\text { outcomes }\end{array}$ & $\begin{array}{l}\text { Task/s } \\
\text { owner }\end{array}$ & $\begin{array}{l}\text { A person } \\
\text { responsib } \\
\text { le for } \\
\text { iteration/s }\end{array}$ & $\begin{array}{c}\text { Agile } \\
\text { management } \\
\text { master/special } \\
\text { ist }\end{array}$ & $\begin{array}{c}\text { Ordinary } \\
\text { team } \\
\text { member } \\
\text { s }\end{array}$ \\
\hline $\begin{array}{c}\text { Formation of a } \\
\text { cross-functional } \\
\text { project } \\
\text { management team }\end{array}$ & $\mathrm{P} / \mathrm{I}$ & $\mathrm{MD}$ & Inf & Inf & C & Inf \\
\hline $\begin{array}{l}\text { Making decisions } \\
\text { on agile project } \\
\text { management in } \\
\text { administration }\end{array}$ & C & MD & Inf & Inf & $P / I$ & $P / l$ \\
\hline Approval of a team & $P / I$ & MD & Inf & Inf & Inf & Inf \\
\hline $\begin{array}{l}\text { Team meeting to } \\
\text { discuss the rules of } \\
\text { agile project } \\
\text { management }\end{array}$ & $P / I$ & $P / I$ & $\mathrm{P} / \mathrm{I}$ & $\mathrm{P} / \mathrm{l}$ & $\mathrm{P} / \mathrm{I} / \mathrm{C}$ & $\mathrm{P} / \mathrm{l}$ \\
\hline $\begin{array}{l}\text { Assigning roles to } \\
\text { the team }\end{array}$ & MD & $\mathrm{P} / \mathrm{Inf}$ & $\mathrm{P} / \mathrm{Inf}$ & P/Inf & $\mathrm{P} / \mathrm{C}$ & $\mathrm{P} / \mathrm{Inf}$ \\
\hline
\end{tabular}

Key: MD - makes decisions; P - participates; C - co-ordinates; I - implements; Inf - informs

During Stage 2. Implementing agile project management, the team is made familiar with the prepared project launch document. A list of requirements is prepared on this basis. The overall project work or activities are formulated as tasks. Each task is broken up into smaller parts - iterations. Each iteration and task is framed in an indicative timeline. Tasks are constantly prioritized and iterations for their execution are highlighted accordingly. Whenever possible, several iterations are performed simultaneously. An outcome measurement instrument is determined for each task. Iterations are currently assigned. In accordance with the adopted rules for agile project management, team meetings are held to discuss progress, problems and necessary changes. Various agile management tools are applied to improve overall coordination of iteration implementation and to facilitate communication and control. Adjustments are made and progress is reported. Minimum documentation is prepared to meet the requirements of the financial instrument, of external audit and control bodies, and of legislation. Retrospective meetings are held to share lessons learned. A large number of steps are performed repeatedly, i.e. cyclically.

Table 2. Responsibility matrix in Stage 2. Implementing agile project management.

\begin{tabular}{|c|c|c|c|c|c|c|}
\hline Role & $\begin{array}{c}\text { Project } \\
\text { owner }\end{array}$ & $\begin{array}{c}\text { Public owner } \\
\text { of project } \\
\text { outcomes }\end{array}$ & $\begin{array}{c}\text { Task/s } \\
\text { owner }\end{array}$ & $\begin{array}{c}\text { A person } \\
\text { responsibl } \\
\text { e for } \\
\text { iteration/s }\end{array}$ & $\begin{array}{c}\text { Agile } \\
\text { management } \\
\text { master/special } \\
\text { ist }\end{array}$ & $\begin{array}{c}\text { Ordinary } \\
\text { team } \\
\text { member } \\
\text { s }\end{array}$ \\
\hline $\begin{array}{c}\text { Introducing the } \\
\text { project launch } \\
\text { document to the } \\
\text { team }\end{array}$ & $\mathrm{I}$ & $\operatorname{Inf}$ & $\operatorname{Inf}$ & $\operatorname{Inf}$ & $\operatorname{Inf}$ \\
\hline $\begin{array}{c}\text { Formulating project } \\
\text { tasks and iterations }\end{array}$ & $\mathrm{MD}$ & $\mathrm{Inf}$ & $\mathrm{P} / \mathrm{l}$ & $\mathrm{P} / \mathrm{l}$ & $\mathrm{P} / \mathrm{l}$ & $\mathrm{P} / \mathrm{I}$ \\
\hline
\end{tabular}




\begin{tabular}{|c|c|c|c|c|c|c|}
\hline $\begin{array}{l}\text { Defining indicative } \\
\text { timeline for the } \\
\text { execution of each } \\
\text { iteration and each } \\
\text { task }\end{array}$ & C & & MD & MD & Inf & $P / I$ \\
\hline $\begin{array}{l}\text { Defining progress } \\
\text { indicators for } \\
\text { individual tasks }\end{array}$ & C & & MD & $\mathrm{P} / \mathrm{l}$ & Inf & $P / l$ \\
\hline Prioritizing tasks & MD & & $\mathrm{P} / \mathrm{l}$ & $P$ & $\mathrm{P} / \mathrm{C}$ & $P$ \\
\hline $\begin{array}{l}\text { Assigning priority } \\
\text { iterations }\end{array}$ & C & & MD & $\mathrm{P} / \mathrm{I}$ & Inf & I \\
\hline Iteration execution & $\mathrm{P} / \mathrm{C}$ & & $\mathrm{P}$ & I & Inf & I \\
\hline $\begin{array}{l}\text { Holding ongoing } \\
\text { team meetings }\end{array}$ & P/MD & & $\mathrm{P} / \mathrm{C}$ & $\mathrm{P} / \mathrm{Inf}$ & $P$ & P/Inf \\
\hline $\begin{array}{l}\text { Checking for } \\
\text { necessary } \\
\text { adjustment to } \\
\text { iteration execution }\end{array}$ & MD & & C & I & Inf & I/Inf \\
\hline $\begin{array}{l}\text { Regular meetings } \\
\text { to evaluate } \\
\text { progress on tasks }\end{array}$ & Inf/MD & & $\mathrm{P} / \mathrm{l}$ & $\mathrm{P} / \mathrm{Inf}$ & $\mathrm{P} / \mathrm{C}$ & $\mathrm{P} / \mathrm{Inf}$ \\
\hline $\begin{array}{l}\text { Checks for } \\
\text { compliance with the } \\
\text { required outcome of } \\
\text { the task }\end{array}$ & Inf/MD & & $\mathrm{P} / \mathrm{l}$ & $\mathrm{P} / \mathrm{Inf}$ & $\mathrm{P} / \mathrm{C}$ & $\mathrm{P} / \mathrm{Inf}$ \\
\hline $\begin{array}{l}\text { Check whether an } \\
\text { adjustment or a } \\
\text { change in the } \\
\text { project plan is } \\
\text { acceptable }\end{array}$ & MD & & $\mathrm{P} / \mathrm{l}$ & $\mathrm{P} / \mathrm{Inf}$ & C & $\mathrm{P} / \mathrm{Inf}$ \\
\hline $\begin{array}{l}\text { Making adjustments } \\
\text { or changes in the } \\
\text { project plan }\end{array}$ & MD & & $\mathrm{P} / \mathrm{l}$ & $\mathrm{P} / \mathrm{l}$ & C & $P / I$ \\
\hline $\begin{array}{c}\text { Project } \\
\text { documentation }\end{array}$ & MD & & $\mathrm{P} / \mathrm{l}$ & $P / l$ & C & Inf \\
\hline $\begin{array}{l}\text { Retrospective } \\
\text { meeting }\end{array}$ & $\mathrm{P} / \mathrm{l}$ & Inf & $\mathrm{P} / \mathrm{l}$ & $\mathrm{P} / \mathrm{l}$ & $P / I$ & $P / I$ \\
\hline
\end{tabular}

Key: MD - makes decisions; P - participates; C - co-ordinates; I - implements; Inf - informs.

Stage 3. Internal monitoring studies the project history. Within team meetings, iteration execution is reported and the level of achieving the progress indicators of individual tasks is periodically reported. Conformity checks are carried out and adjustment recommendations are made, incl. organizational. Monitoring is a tool for continuous adaptation and improvement. During one of the retrospective meetings, part of Stage 2, monitoring lessons shared within the organization through project stories are defined. 
Table 3. Responsibility matrix in Stage 3. Internal monitoring.

\begin{tabular}{|c|c|c|c|c|c|c|}
\hline Step & $\begin{array}{c}\text { Project } \\
\text { owner }\end{array}$ & $\begin{array}{c}\text { Public owner } \\
\text { of project } \\
\text { outcomes }\end{array}$ & $\begin{array}{c}\text { Task/s } \\
\text { owner }\end{array}$ & $\begin{array}{c}\text { A person } \\
\text { responsibl } \\
\text { e for } \\
\text { iteration/s }\end{array}$ & $\begin{array}{c}\text { Agile } \\
\text { management } \\
\text { master/special } \\
\text { ist }\end{array}$ & $\begin{array}{c}\text { Ordinary } \\
\text { team } \\
\text { member } \\
\mathrm{S}\end{array}$ \\
\hline $\begin{array}{c}\text { Reporting on } \\
\text { progress indicators } \\
\text { for individual tasks }\end{array}$ & $\mathrm{C}$ & $\mathrm{Inf}$ & $\mathrm{P} / \mathrm{I}$ & $\mathrm{P} / \mathrm{Inf}$ & $\mathrm{P} / \mathrm{Inf}$ & $\mathrm{P} / \mathrm{Inf}$ \\
\hline Conformity checks & $\mathrm{MD} / \mathrm{Inf}$ & & $\mathrm{P} / \mathrm{I}$ & $\mathrm{P} / \mathrm{I}$ & $\mathrm{C}$ & $\mathrm{P} / \mathrm{I}$ \\
\hline Adaptive monitoring & $\mathrm{MD}$ & & $\mathrm{P} / \mathrm{I} / \mathrm{Inf}$ & $\mathrm{P} / \mathrm{I} / \mathrm{Inf}$ & $\mathrm{C}$ & $\mathrm{P} / \mathrm{I} / \mathrm{Inf}$ \\
\hline Monitoring lessons & $\mathrm{MD}$ & $\mathrm{Inf}$ & $\mathrm{P} / \mathrm{Inf}$ & $\mathrm{P} / \mathrm{Inf}$ & $\mathrm{P} / \mathrm{C}$ & $\mathrm{P} / \mathrm{Inf}$ \\
\hline
\end{tabular}

Key: MD - makes decisions; P - participates; C - co-ordinates; I - implements; Inf - informs.

Stage 3. Internal monitoring is carried out in parallel with Stage 2, and in technological aspect the team has the autonomy to organize the project monitoring according to the project needs, team vision and the requirements of the financing instrument in order to provide reasonable assurance that the planned outcomes will be achieved.

Organizationally, the methodology is agile and enables teams within their competencies, organizational experience and expertise to have the autonomy to apply other stages and iterations for agile project management, taking into account its specific features.

The outcomes of implementing the concept of agile project management methodology in the public sector depend on several key conditions, namely:

- Creating an environment in an organization and making it project-oriented is a prerequisite for implementing the agile project management methodology in the public sector. This means that most of the workflows must be interpreted as projects within which a qualitative result is to be achieved, i.e. to turn the organization into a result-oriented one.

- Creating an environment for applying this methodology requires an adequate "tip tone", i.e. the management team and management positions to delegate rights and responsibilities and to enable independent decision-making by the teams. This condition is entirely in the context of agile project management where in business organizations projects trust project management teams. Trust is key to the success of the agile methodology.

- On the one hand implementing the agile project management methodology in the public sector implies an organizational attitude for teamwork and a high degree of delegation. On the other hand it allows external stakeholders to participate in the project team work whenever possible.

- It may be fully or partially implemented. Full implementation is recommended in the presence of independent decision-making by the project team, the absence of restrictive requirements by the funding organization and compliance with the project-related regulatory framework. Partial implementation is recommended when any of the provisions of the methodology contradicts the requirements of the financial instrument and the specifics of the project.

- Agile project management methodology implementation requires a willingness within the organization to innovate, make organizational change in project management, and a high degree of independent decisionmaking by the teams according to their competencies. Organizational capacity to manage and adapt to change is needed, i.e. perceiving the organization as a flexible, adaptable and learning system made up of intelligent people.

- A comprehensive team-based problem-solving approach that: considers all members to be qualified and valuable participants in team management; relies on the collective ability of individual teams as the main mechanism for solving problems; restricts advance planning, focusing on rapid adaptation to dynamically 
changing conditions.

- Administrative practice of minimizing the document flow in accordance with the requirements of the regulatory framework, financial instrument and control bodies.

- Operational control, oriented to results, not to work done. Determining the limits of internal and external control when establishing the order of the project.

The proposed concept of an agile project management methodology in the public sector is open, both in terms of its practical implementation and in terms of the development of science and the integration of research achievements in it. It is not perfect, but it is the first attempt to adapt the principles of agile project management in the public sector and will be subject to further research.

\section{DISCUSSION - IMPLEMENTATION CAPACITY}

The proposed approach to agile project management is particularly challenging for both large and small organizations. For the large ones - because they have complex structures, a great number of internal rules and procedures and have already entered a stage of maturity whereby they have a well-established (nonAgile) culture. Small organizations at first glance seem more adaptable, but they also have less absorption capacity for organizational innovation.

The main challenges agile project management in the public sector faces can be identified as follows:

\section{- Team members' knowledge and experience}

When agile project management is introduced in an organization, staff are likely to have little or no experience. At the same time, it is necessary to create teams that need to work in a completely different way. This means they will be trained and/or recruited for these teams. In both cases, the HR office will have additional obligations to clarify what competencies employees need, what responsibilities they will have, what their job descriptions should be. The modern approach to solving this problem is the use of a competency model (Skorková, 2016c). It describes several competency groups and becomes a leader in both recruitment and career development.

\section{- The behaviour of leaders in an organization}

In traditional management, due to its hierarchical nature, the direction is well established: managers make decisions; low levels implement them and report them. Agile practices are reversing the process, although traditional managers hardly give up the right to decision-making. They should provide conditions for the teams, not tell them what to do. This is difficult to understand and sometimes takes time.

Teams in turn also do not have the necessary attitude to make their own decisions. They wait for the managers' approval because they recognize them as the most important stakeholders. However, these should be the clients/users of public services. This is also difficult to understand and takes time.

\section{- Consistency of efforts}

Applying agile methodolgy at a corporate level is a long-term investment. It will make a return, although not in the short run (Chalanges of Agile Adoption, 2015a). Therefore, Agile must be gradually introduced into an administration. It is recommended to invest efforts in one team and practice should be spread to other teams only when it is successful.

An organization should also make it possible to reconfigure processes in order to provide team autonomy, at least within certain limits. The barrier here is related to both public sector regulations and the routine accumulated in most organizations that are highly resistant to similar changes.

Transformation within organizations is a difficult process because people always think they are losing something, regardless of the fact if the loss is real or imaginary (Recognizing the 12 Failure Modes in Agile Transformation). This applies to both individuals and managers. Usually, within the first stage of transformation, individual employees feel stressed and discouraged as their status changes. At this stage it is important to realize that they need to give up their attitudes. During the second stage of change, they accept the differences between the old and the new. During the third stage, they become aware of the changes and begin to evaluate their benefits.

Transformation at organizational level also takes place in several stages. An indicative example in this regard is the example of the Michigan State Administration in the United States, which in 1999 decided to introduce project management as an approach to implement its activities (traditional rather than agile projects). The process developed in two stages and took several years (Pyne, Rigby, 2002a). During the 
first stage, a project management base and appropriate organizational conditions were created, incl. infrastructure. A core team was assigned to define and build a project management framework for all units of state administration. Employees of the Project Management Office were recruited and its mission and vision were developed and adopted. Qualified project managers were hired to manage large, complex projects. A project management training programme was developed. The methodology for PM (current at that time) was published and disseminated within the administration. Larger local offices set up decentralized departments for PM at a local level together with businesses. This provided the opportunity to create a network and use the project management experience gained in business and industry (transferring business experience into the public sector). A centralized forum was created through the Michigan Project Management website. This website was used to promote project management all over the state and to provide project management information.

During the second stage, depth, breadth and support for project management in daily activities was achieved. The goal was to make it a habit for managers at lower levels. The project management methodology was revised, the mechanisms for integrating the methodology and tools were updated and improved. Many additional trainings were carried with relation to PM and for their application in new areas. Gaps in PM training were discussed. Auxiliary staff in project management was also trained.

A Center for Excellence in Project Management was established in Michigan. It quickly became a leadership forum. It focused on the implementation and integration of methodology, tools and training with lessons learned, best practices and knowledge transfer. As the project management environment continued to evolve in the state, the Center for Excellence was assigned to use shared project management experience between project teams, to provide repositories for project techniques, the project management evaluation process and continuous improvement (Terziev, Georgiev, 2019a-d; Terziev, Georgiev, 2018b).

\section{CONCLUSION}

The above mentioned prerequisites for implementing the agile project management methodology in the public sector are in fact part of the organizational culture that is critical to the success of an administration. The organizational culture of a modern administration requires the ability to adapt quickly, to have an attitude towards continuous learning, to be proactive, to be open to collaboration, teamwork, trust and mutual support, positive energy and optimism. Thus, mature organizations effectively overcome barriers such as resistance to change, poor communication, and strong bureaucracy inherent in vertical hierarchical structures.

The above mentioned barriers were pointed out to be an obstacle when the present project management methodology was given approbation by representatives of various regional and local public organizations, as well as by programme, project and portfolio management experts at the Bulgarian Institute for Standardization. Despite these obstacles, the overall assessment is that the methodology has huge potential for improving the efficiency and effectiveness of work (Terziev, Georgiev, 2017; Terziev, Nichev, Stoyanov, Georgiev, 2017a).

In a broader sense, the issue of organizational maturity develops into the problem of maturity in societies. Successful implementation of the agile methodology requires motivated and constant involvement of stakeholders and, above all, citizens as users of public services - something that Bulgarian society still lacks.

In an ideal world, citizens as users of public services would be sufficiently motivated to participate actively and responsibly in processes affecting the local community development (Cooke, 2018a). This means being well aware of the issues at a local level and participating in the democratic process of prioritizing local needs (exercising their right to vote), as well as being objective enough to provide insight into the potential solution to these problems, and being competent enough to understand the political, regulatory and technical limitations of these decisions. In this perfect scenario, citizens would be a permanent partner of public authorities. They are the component required for the external integration of project teams (Terziev, 2019d-s).

\section{REFERENCE LIST}

Karaj, A., Little, J. (2013). Transforming a Public Sector Company: From Stone Age to Agile. Agile Conference (AGILE), pp. 74-81.

Ribeiro, A, Domingues, L. (2018). Acceptance of an agile methodology in the public sector, Procedia Computer Scienc, 2018. 
Agile handbook Philosophie. (n.d.). Retrieved 2019, from

http://teaching.csse.uwa.edu.au/units/CITS5551/readings/agile-handbook.pdf

Agile Project Management QuickStart Guide. (2014). ClydeBank Media LLC.

Altukhova, N.F., Vasileva, E.V., Slavin, B.B. (2016). Concept for new approach to project management in the activitirs of public servants. Business Informatics, 2016a No 4(38) p DOI:10.17323/19980663.2016.4.60.69, P.60-69.

Beck, K. (2001). Manifesto for Agile Software Development. Agile Alliance.

Brechner, E. (2015). Agile Project Management with Kanban. Washington: Microsoft Press.

Torrecilla-Salinas, C.J., Sedeño, J., Escalona, M.J, Mejías, M. (2013). Agile in Public Administration: Oxymoron or reality? An experience report. in CEUR Workshop Proceedings, vol. 1017, pp. 1-8.

Chalanges of Agile Adoption. (2015a). Retrieved from Intelliware Development Inc.: http://www.intelliware.com/wp-content/uploads/Challenges-of-Agile-Adoption.pdf.

Cooke, J.L. (2018a). "Introduction". The Power of the Agile Business Analyst, Second Edition: 30 Surprising Ways a Business Analyst Can Add Value to Your Agile Development Team. Cambridgeshire, United Kingdom: IT Governance Publishing, Ely, 2nd ed.

Conforto, E.C., Salum, F., Amaral, D.C., S. L. da Silva, L. F. M. de Almeida. (2014a). Can agile project management be adopted by industries other than software development? Proj. Manag. J., vol. 45, no. 3, pp. pp. 21-28.

Government Extension to the PMBOK® Guide Third Edition. (2002). Project Management Institute, Inc.

Hass, K. (2007). The Blending of Traditional and Agile Project Management. Project Smart.co.uk.

Nuottila, J., Aaltonen, K., Kujala, J. (2016a). Challenges of adopting agile methods in a public organization. IJISPM-INTERNATIONAL J. Inf. Syst. Proj. Manag., vol. 4, no. 3, pp. 65-85.

Roses, K., Windmöller, A., E. A. do Carmo. (2016a). Favorability conditions in the adoption of agile method practices for software development in a public banking. J. Inf. Syst. Technol. Manag., vol. 13, no. 3, pp. 439-458.

Kaczorowska, A. (2015a). Traditional and agile project management in public sector and ICT. Computer Science and Information Systems (FedCSIS), Federated Conference.

Wisitpongphan, N., Khampachua, T. (2016b). Agile in public sector: Case study of dairy farm management projects. 13th Int. Jt. Conf. Comput. Sci. Softw. Eng., pp. 1-5.

Powner, D. (2012). Software Development: Effective Practices and Federal Challenges in Applying Agile Methods. Washington, DC.: United States Government Accountability Office.

Pyne, L.S., Rigby, B. (2002a). Implementing a project management culture in a government organization. Paper presented at Project Management Institute Annual Seminars \& Symposium,. San Antonio, TX. Newtown Square,: PA: Project Management Institute.

Recognizing the 12 Failure Modes in Agile Transformation. (n.d.). Retrieved from CA technologies https://docs.broadcom.com/docs-and-downloads/content/dam/ca/us/files/ebook/recognizing-thetwelve-failure-modes-in-agile-transformation.pdf

Schwaber, K. (2004). Agile project management with Scrum. Redmond: Microsoft Press.

Skorková, Z. (2016c). Competency models in public sector. 3rd International Conference on New Challenges in Management and Organization: Organization and Leadership, 2 May 2016, Dubai, UAE.

Sutherland, J. (2014b). Scrum. The Art of Doing Twice the Work in Half the Time. New York: Crown Busines.

The Five Steps of Lean Implementation. (2019a). Retrieved 2019, from https://www.lean.org/WhoWeAre/LEINewsStory.cfm?NewsArticleld=17.

Owen, R., Koskela, L., Henrich, G., Codinhoto, R. (2006). IsAgile Project ManagementApplicable To Construction? Proceedings 14th AnnualConference of the International Group forLean Construction, Santiago, Chile, 2006, p. 57.

Terziev, V., Georgiev, M. (2019a). Social entrepreneurship: social enterprises and their markets in Bulgaria. // Proceedings of SOCIOINT 2019- 6th International Conference on Education, Social Sciences and 
Humanities 24-26 June 2019- Istanbul, Turkey, International Organization Center of Academic Research, Istanbul, Turkey, 2019, pp. 267-272, ISBN: 978-605-82433-6-1.

Terziev, V., Georgiev, M. (2019b). Social entrepreneurship: support for social enterprises in Bulgaria. // Proceedings of SOCIOINT 2019-6th International Conference on Education, Social Sciences and Humanities 24-26 June 2019- Istanbul, Turkey, International Organization Center of Academic Research, Istanbul, Turkey, 2019, pp. 273-278, ISBN: 978-605-82433-6-1.

Terziev, V., Georgiev, M. (2019c). Current initiatives to promote social entrepreneurship in Bulgaria. // Proceedings of SOCIOINT 2019-6th International Conference on Education, Social Sciences and Humanities 24-26 June 2019- Istanbul, Turkey, International Organization Center of Academic Research, Istanbul, Turkey, 2019, pp. 279-286, ISBN: 978-605-82433-6-1.

Terziev, V., Georgiev, M. (2019d). Implementation of national and regional policies for development of social entrepreneurship in Bulgaria. // Proceedings of SOCIOINT 2019- 6th International Conference on Education, Social Sciences and Humanities 24-26 June 2019- Istanbul, Turkey, International Organization Center of Academic Research, Istanbul, Turkey, 2019, pp. 287-300, ISBN: 978-60582433-6-1.

Terziev, V., Georgiev, M. (2018b). Efficient management as optimization of the organization. // Proceedings of INTCESS2018- 5th International Conference on Education and Social Sciences 5-7 February 2018Istanbul, Turkey, International Organization Center of Academic Research, www.ocerints.org, Istanbul, Turkey, 2018, pp. 452-461, ISBN: 978-605-82433-2-3.

Terziev, V., Georgiev, M. (2017). Highlights of the evolution of the 'Balanced Scorecard' idea as a model for managing strategy development and control. // SOCIOINT 2017- 4th International Conference on Education, Social Sciences and Humanities 10-12 July 2017- Dubai, UAE, OCERINT- International Organization Center of Academic Research, Istanbul, Turkey, 2017, pp. 607-610, ISBN: 978-60582433-1-6.

Terziev, V., Nichev, N., Stoyanov, E., Georgiev, M. (2017a). A general principle of the development process of balanced scorecards as an instrument of control. // Proceedings of ADVED 2017- 3rd International Conference on Advances in Education and Social Sciences 9-11 October 2017- Istanbul, Turkey. International Organization Center of Academic Research, www.ocerint.org, 2017, pp. 690-694, .ISBN: 978-605-82433-0-9.

Terziev, Venelin. (2019d). The legacy for the beginning of the market economy transition in Bulgaria. // Proceedings of SOCIOINT 2019-6th International Conference on Education, Social Sciences and Humanities 24-26 June 2019- Istanbul, Turkey, International Organization Center of Academic Research, Istanbul, Turkey, 2019, pp. 301-308, ISBN: 978-605-82433-6-1.

Terziev, Venelin. (2019e). Policies for building a functioning labour market in Bulgaria. // Proceedings of SOCIOINT 2019- 6th International Conference on Education, Social Sciences and Humanities 24-26 June 2019- Istanbul, Turkey, International Organization Center of Academic Research, Istanbul, Turkey, 2019, pp. 309-316, ISBN: 978-605-82433-6-1.

Terziev, Venelin. (2019f). Factors influencing employment and unemployment policies in Bulgaria. // Proceedings of SOCIOINT 2019- 6th International Conference on Education, Social Sciences and Humanities 24-26 June 2019- Istanbul, Turkey, International Organization Center of Academic Research, Istanbul, Turkey, 2019, pp. 317-323, ISBN: 978-605-82433-6-1.

Terziev, Venelin. (2019g). The role of business in society. // Proceedings of SOCIOINT 2019- 6th International Conference on Education, Social Sciences and Humanities 24-26 June 2019- Istanbul, Turkey, International Organization Center of Academic Research, Istanbul, Turkey, 2019, pp. 324-330, ISBN: 978-605-82433-6-1.

Terziev, Venelin. (2019h). Social entrepreneurship in Bulgaria and Europe. // Proceedings of SOCIOINT 2019- 6th International Conference on Education, Social Sciences and Humanities 24-26 June 2019Istanbul, Turkey, International Organization Center of Academic Research, Istanbul, Turkey, 2019, pp. 337-345, ISBN: 978-605-82433-6-1.

Terziev, Venelin. (2019i). The role of social policy in economic development. // Proceedings of SOCIOINT 2019- 6th International Conference on Education, Social Sciences and Humanities 24-26 June 2019Istanbul, Turkey, International Organization Center of Academic Research, Istanbul, Turkey, 2019, pp. 396-404, ISBN: 978-605-82433-6-1. 
Terziev, Venelin. (2019j). Flows of labor force and types of labor markets in the transition economy. // Proceedings of SOCIOINT 2019-6th International Conference on Education, Social Sciences and Humanities 24-26 June 2019- Istanbul, Turkey, International Organization Center of Academic Research, Istanbul, Turkey, 2019, pp. 405-418, ISBN: 978-605-82433-6-1.

Terziev, Venelin. (2019k). The good practices in the regulation of social development. // Proceedings of SOCIOINT 2019- 6th International Conference on Education, Social Sciences and Humanities 24-26 June 2019- Istanbul, Turkey, International Organization Center of Academic Research, Istanbul, Turkey, 2019, pp. 419-429, ISBN: 978-605-82433-6-1.

Terziev, Venelin. (2019l). Methodological approach to research and evaluate the main states and transitions on the labor market. // Proceedings of SOCIOINT 2019- 6th International Conference on Education, Social Sciences and Humanities 24-26 June 2019- Istanbul, Turkey, International Organization Center of Academic Research, Istanbul, Turkey, 2019, pp. 430-438, ISBN: 978-605-82433-6-1.

Terziev, Venelin. (2019m). The transition labor market- competitiveness of the employee. // Proceedings of SOCIOINT 2019- 6th International Conference on Education, Social Sciences and Humanities 24-26 June 2019- Istanbul, Turkey, International Organization Center of Academic Research, Istanbul, Turkey, 2019, pp. 439-451, ISBN: 978-605-82433-6-1.

Terziev, Venelin. (2019n). Retraining of the discharged and the ones leaving active military service as a tool for their social and professional mobility. // Proceedings of SOCIOINT 2019-6th International Conference on Education, Social Sciences and Humanities 24-26 June 2019- Istanbul, Turkey, International Organization Center of Academic Research, Istanbul, Turkey, 2019, pp. 452-461, ISBN: 978-605-82433-6-1.

Terziev, Venelin. (2019o). Social technology as a method for management of the social processes. // Proceedings of SOCIOINT 2019- 6th International Conference on Education, Social Sciences and Humanities 24-26 June 2019- Istanbul, Turkey, International Organization Center of Academic Research, Istanbul, Turkey, 2019, pp. 331-336, ISBN: 978-605-82433-6-1.

Terziev, Venelin. (2019p). The role and place of social programming in public governance. // Proceedings of SOCIOINT 2019- 6th International Conference on Education, Social Sciences and Humanities 24-26 June 2019- Istanbul, Turkey, International Organization Center of Academic Research, Istanbul, Turkey, 2019, pp. 331-336, ISBN: 978-605-82433-6-1.

Terziev, Venelin. (2019q). Assessment of the effectiveness of social programing. // Proceedings of SOCIOINT 2019- 6th International Conference on Education, Social Sciences and Humanities 24-26 June 2019- Istanbul, Turkey, International Organization Center of Academic Research, Istanbul, Turkey, 2019, pp. 363-373, ISBN: 978-605-82433-6-1.

Terziev, Venelin. (2019r). Social efficiency as a measure of social activities. // Proceedings of SOCIOINT 2019- 6th International Conference on Education, Social Sciences and Humanities 24-26 June 2019Istanbul, Turkey, International Organization Center of Academic Research, Istanbul, Turkey, 2019, pp. 363-373, ISBN: 978-605-82433-6-1.

Terziev, Venelin. (2019s). Effects of the impact of the active policies on the labor market. // Proceedings of SOCIOINT 2019- 6th International Conference on Education, Social Sciences and Humanities 24-26 June 2019- Istanbul, Turkey, International Organization Center of Academic Research, Istanbul, Turkey, 2019, pp. 381-395, ISBN: 978-605-82433-6-1. 